\title{
Prognostic Factors in Extremity Soft Tissue Sarcoma Patients Treated with Preoperative Radiotherapy
}

\author{
Berrin Inanc, $\mathrm{MD}^{1}$, Kubilay Inanc, $\mathrm{MD}^{2}$ \\ ${ }^{1}$ University of Health Sciences, Istanbul Education and Research Hospital, Department of Radiation Oncology, Istanbul, \\ TR-34098, Turkey, byalcin77@ hotmail.com \\ ${ }^{2}$ University of Health Sciences, Sisli Hamidiye Etfal Education and Research Hospital, Department of Radiation Oncology, \\ Istanbul, TR-34377, Turkey, kinanc@ hotmail.com
}

*Correspondence author - Berrin Inanc, MD, byalcin77@ hotmail.com

Received 03 February 2019;

Accepted 25 February 2019;

Published 01 March 2019

\begin{abstract}
Purpose: The purpose of the study was to investigate the prognostic factors and survival after preoperative radiotherapy in Extremity Soft Tissue Sarcomas (ESTS). Materials and Methods: In this retrospective study, all patients treated for an extremity sarcoma with pre-operative radiotherapy followed by surgery. Results: The mean follow-up for all 24 ESTS patients was 15.5 (range: 10-39 months). At last follow-up, 9 patients $(37 \%)$ were alive, 15 patients $(62 \%)$ had died of distant disease progression. Among the patients died, there were 15 with metastatic relapse (13 lung and 2 cranial metastasis), 5 with both local and metastatic recurrence. The median OS was 16 month. The 2 -years actuarial OS rate and 3-years OS rate were $39 \%$ and $26 \%$, respectively. The median RFS was 14(12.5-15.4) month. The 2-years and 3-years RFS rate was 71\%.The median MFS was 12 months. The 2-years and 3-years MFS rate were 33\%, 17\%, respectively. The effects of age, sex, histopathologic type, tumor size, tumor localization, tumor grade, tumor depth, radiation doses and recestion margin on OS, RFS, MFS were not observed. In univariate and multivariate model, it was observed that recurrence decreased OS time significantly ( $\mathrm{p}<0.05$ ). Conclusion: Recurrens and metastasis are strong and negative prognostic factor for survival in extremity soft tissue sarcoma patients.
\end{abstract}

Keywords: Extremity Soft Tissue Sarcoma, Preoperative radiotherapy, Prognostic factor, Survival

\section{Introduction}

Soft tissue sarcoma may originate any connective tissue site in the body. Approximately three forth of soft tissue sarcomas located in extremities ${ }^{[1]}$. Soft tissue sarcoma of the extremities (ESTS) is larger and recognized later due to painless presentations and rarity of the disease.

In the past, most ESTS patients have undergone surgery and postoperative radiotherapy. However preoperative radiotherapy (RT) and surgery are now the most favored option for ESTS. The importance of preoperative RT for ESTS has been validated by the "NCCN ${ }^{[2]}$ and $\mathrm{ESMO}^{[3] ", ~ g u i d e l i n e s . ~ B o t h ~ g u i d e l i n e s ~ h a v e ~}$ confirmed that the administration of preoperative radiotherapy and negative surgery margins increases the local control rate. Because preoperative RT tumor volume and dose are smaller than postoperative RT.

Another controversial issue is the toxicity. While postoperative RT is associated with late side toxicities, such as limb edema, fibrosis, loss of subcutaneous tissue and fractures ${ }^{[4,5]}$, preoperative RT is associated with wound healing which is more acute side toxicity ${ }^{[6,7,8]}$. In the long-term follow-up of ESTS wound healing is relatively manageable and reversible but late toxicities more important ${ }^{[9,10]}$.

The purpose of this study was to analyze the data of ESTS patients who were treated with preoperative radiotherapy and surgery between 2011 and 2018 to assess prognostic factors and follow-up survival.

\section{Material and Methods}

This study was conducted at the Department of Radiation Oncology, Istanbul Research and Education Hospital and Sisli Hamidiye Etfal Research and Education Hospital in Istanbul, Turkey in accordance with the principles of the Declaration of Helsinki. A total of 24 cancer patients with ESTS who were admitted to the Radiation Oncology Department for preoperative RT and surgery between 2011 and 2018 were evaluated retrospectively. Exclusion criteria included metastatic disease, the patient who insufficient clinical information in records and age $<18$ years. 
Data collected from the patient record system were details of patient sex, age, median tumor size (at diagnosis), histopathological type of the tumor, tumor localization, tumor grade, tumor depth, median radiotherapy doses, radiotherapy modalities, resection margins, overall survival and recurrence-free survival, metastasis-free survival.

The primary endpoint was acute (occurrence of wound healing complication) and late toxicities (limb edema and fibrosis, bone fracture). Wound healing complication was defined as any local complication of the surgical area, hospital readmission. Wound healing complication assessment 30 days after resection by a surgeon and a radiation oncologist. Late toxicity assessment according to the RTOG/EORTC Late Radiation Morbidity Scoring Scheme ${ }^{[11]}$.

The secondary endpoint was overall survival(OS), recurrence-free survival(RFS) and metastasis-free survival(MFS). The patients' survival data were obtained from the hospital records, and patients lost to follow-up were contacted to obtain information about their conditions. OS was defined as the time between the date of diagnosis and that of the last contact or death. RFS, MFS was the period between at the date of diagnosis and the time of tumor recurrence local and metastasis, respectively. Clinical local recurrence and metastasis were confirmed with CT/MRI and biopsy.

Histological subtypes were defined according to the latest World Health Organization classification of soft tissues tumors. Tumor size was measured preoperatively on MRI. National Federation of Centers for Combating Cancer has defined tumor aggressiveness as high, intermediate or low grade. The status of resection margins was categorized according to the UICC ' $R$ '” classification ${ }^{[12]}$.

\section{Radiation Planning and Volume Definition}

The radiation oncologist defined the gross tumor volume (GTV) using magnetic resonance imaging (MRI) and computerized tomography (CT). The clinical target volume (CTV) extended $4 \mathrm{~cm}$ proximally and distally from GTV and $1.5 \mathrm{~cm}$ radially and included peritumoral edema. The planning target volume (PTV) was created with a $0.5 \mathrm{~cm}$ to all direction. Preoperative RT at a dose of $50 \mathrm{~Gy}$ in 25 daily fractions over five weeks was administered. The treatment objectives specified that $95 \%$ of prescribed dose should encompass the PTV and maximum dose should not exceed $107 \%$, according to ICRU Report $50^{[13]}$. Beams energies were 6-18 MV and bolus was used to require patient (i.e., skin involved). Patients were positioned for CT simulation in a neutral position, and the affected limb was immobilized in a vacuum bed. RT avoidance structures included the fascia, skin bone, joint and normal musculature.

All patients were treated with preoperative RT and surgery. An oncologic surgeon performed Limb-sparing definitive tumor resection. During the treatment period, all patients were examined by a radiation oncologist. Patients were followed with MRI and chest CT every six months for five years and then yearly

\section{Statistical Analysis}

The Statistical Package for Social Sciences (SPSS) for Windows 22.0 (SPSS, Inc., Chicago, IL, USA) was used for the statistical analysis. Patient and treatment characteristics were defined with descriptive statistics. The survival rates were calculated according to the Kaplan-Meier method. A univariate and multivariate analysis (Cox regression analysis) was used to evaluate the independent risk factors that affected survival. $\mathrm{P}$ values $\leq 0.05$ were accepted as statistically significant.

\section{Results}

There were 2(8\%) female and 22(92\%) male patients. A total of 24 patients with a median age of 28.5 years (range: 19-52) were included in this study. Median tumor size (at diagnosis) were 9.2 $\mathrm{cm}$ (range: 6-14 cm).Most were classified as malign fibrous histiocytoma/ undifferentiated pleomorphic sarcoma (n: 6, 25\%) and epithelioid sarcoma/ synovial sarcoma/ malign peripheral nerve tumor (n: $3,12.5 \%)$ with a variety of other pathological subtypes. Only $3(12.5 \%)$ patients, the tumor was localized in the upper extremity. The remainder (21 patients, $87.5 \%$ ) was localized in the lower extremity. Almost all tumors were high grade (n: 19, $79 \%)$, others were intermediate (n: 3, 13\%) and lower grade (n: 2 , $8 \%$ ). About half of the tumors were superficial localized (n: 14, $58.3 \%$ ), while the other half was deep (n: $10,41.7 \%$ ). Preoperative radiotherapy dose was $50 \mathrm{~Gy}(2 \mathrm{~Gy} / 25$ fraction) in all patients. Seventeen $(70.8 \%)$ patients were treated with 3-dimensional conformal radiotherapy (3-DCRT). Seven patients (29.2\%) were treated with intensity-modulated radiotherapy (IMRT). Neoadjuvant chemotherapy was not given ESTS patient. Surgery was performed after a median of 6 weeks after the last RT fraction. Resection margins were negative (R0), microscopically positive (R1), in 18 (75\%), 6(25\%) patient, respectively. No patient received a postoperative RT boost. Characteristics of the ESTS patient and treatment are presented in Table-1.

Table-1: Patient and treatment characteristics

\begin{tabular}{|c|c|c|}
\hline & $\mathbf{n}$ & $\%$ \\
\hline \multicolumn{3}{|l|}{ Gender } \\
\hline Female & 2 & 8 \\
\hline Male & 22 & 92 \\
\hline Age & $19.0-52.0$ & \\
\hline Tumor size( at diagnosis) & $6.0-14.0$ & \\
\hline \multicolumn{3}{|l|}{ Histological type } \\
\hline Malign mesenchymal tumor & 6 & 25 \\
\hline Undifferantiated pleomorfic sarcoma & 6 & 25 \\
\hline Epiteloide sarcoma & 3 & 12.5 \\
\hline Sinovyal sarcoma & 3 & 12.5 \\
\hline Malign peripheal nerve tumor & 3 & 12.5 \\
\hline Liposarcoma & 2 & 8.3 \\
\hline Fibrosarcoma & 1 & 4.2 \\
\hline \multicolumn{3}{|l|}{ Tumor Localization } \\
\hline Lower Limb & 21 & 87.5 \\
\hline Upper Limb & 3 & 12.5 \\
\hline \multicolumn{3}{|l|}{ Tumor Grade } \\
\hline Low Grade & 2 & 8.5 \\
\hline Intermediate Grade & 3 & 12.5 \\
\hline High Grade & 19 & 79.2 \\
\hline \multicolumn{3}{|l|}{ Tumor Depht } \\
\hline Deep & 10 & 41.7 \\
\hline Superficial & 14 & 58.3 \\
\hline \multicolumn{3}{|l|}{ Radiotherapy Doses } \\
\hline $50 \mathrm{~Gy}$ & 24 & 100 \\
\hline
\end{tabular}




\begin{tabular}{|lcc|} 
Radiotherapy Modalities & 17 & 70.8 \\
3-D Conformal & 7 & 29.2 \\
IMRT & & \\
Resection Margin & & \\
R0 & 18 & 75.0 \\
R1 & 6 & 25.0 \\
Local Recurrence & & \\
No & 17 & 70.8 \\
Yes & 7 & 29.2 \\
Distant Metastasis & & \\
No & & \\
Yes & 8 & 33.3 \\
Brain & 16 & 66.3 \\
Lung & 2 & 8.3 \\
Follow-up & 14 & 60.5 \\
\hline
\end{tabular}

\section{Primary Endpoints}

In this study, wound healing complication was observed in 8 out of 24 patients $(30 \%)$. From these eight patients, mostly consisting of both infection and necrosis. The highest wound healing complication rate $(57 \%)$ was seen among patients with tumors localized in superficial. However, we were not identified prognostic factors for the development of a wound healing complication

No severe late radiation toxicities (> grade 2) were seen among the 24 patients surviving longer than two years. One patient (1.2\%) had skin toxicity, and one patient $(1.2 \%)$ had moderate, and one patient $(1.2 \%)$ had limb edema occurred. No patient suffered a posttreatment fracture (Table-2).
Table 2: Acute and late toxicities

\begin{tabular}{|c|c|c|}
\hline & Grade1-2 & Grade3-4 \\
\hline Acute Toxicities & & \\
\hline Infection & 6 & - \\
\hline Necrosis & 2 & - \\
\hline Late Toxicities & & \\
\hline Limb Edema & 1 & - \\
\hline Fibrosis & 1 & - \\
\hline Bone Fracture & - & - \\
\hline
\end{tabular}

\section{Secondary Endpoints}

The mean length of follow-up for all 24 ESTS patients was 15.5 (range: 10-39 months). At last follow-up, nine patients (37\%) were alive, 15 patients $(62 \%)$ had died of distant disease progression. Among the patients died, there were 15 with metastatic relapse (13 lungs and two cranial metastasis), 5 with both local and metastatic recurrence. The median OS was 16 month. The 2-years actuarial OS rate and 3-years OS rate were $39 \%$ and $26 \%$, respectively. The median RFS was 14(12.5-15.4) month. The 2-years and 3-years RFS rate was $71 \%$. The median MFS was 12 months. The 2-years and 3-years MFS rate were 33\%, $17 \%$, respectively.

The effects of age, sex, histopathologic type, tumor size, tumor localization, tumor grade, tumor depth, radiation doses and recession margin on OS were not observed in the univariate model. The presence of metastases in the brain and lungs decreased the OS time significantly $(\mathrm{p}<0.05)$. In univariate model, it was observed that recurrence decreased OS time significantly $(\mathrm{p}<0.05)$ (Table $3)$.

In multivariate model, it was observed that recurrence decreased OS time significantly $(\mathrm{p}<0.05)($ Table 3$)$.

Table-3: In univariate and multivariate model, recurrence and metastasis decreased survival significantly

\begin{tabular}{|c|c|c|c|c|c|c|c|c|c|c|}
\hline \multirow[b]{3}{*}{ Age } & \multicolumn{5}{|c|}{ Univariate Model } & \multicolumn{5}{|c|}{ Multivariate Model } \\
\hline & \multirow{2}{*}{$\begin{array}{l}\text { HR } \\
1,01\end{array}$} & \multicolumn{3}{|c|}{$\% 95 \mathrm{CI}$} & \multirow{2}{*}{$\begin{array}{c}\mathbf{p} \\
0,790\end{array}$} & \multirow[t]{2}{*}{ HR } & \multicolumn{3}{|c|}{$\% 95 \mathrm{CI}$} & \multirow[t]{2}{*}{$\mathbf{p}$} \\
\hline & & 0,95 & - & 1,07 & & & & & & \\
\hline Sex & 2,01 & 0,26 & - & 15,70 & 0,507 & & & & & \\
\hline Tumor Size & 0,99 & 0,79 & - & 1,25 & 0,936 & & & & & \\
\hline Tumor Localization & 0,37 & 0,05 & - & 2,88 & 0,344 & & & & & \\
\hline Tumor Grade & 6,13 & 0,80 & - & 47,20 & 0,082 & & & & & \\
\hline Tumor Depht & 1,72 & 0,53 & - & 5,61 & 0,367 & & & & & \\
\hline Rt Modalities & 1,02 & 0,33 & - & 3,11 & 0,974 & & & & & \\
\hline Resection Margin & 2,82 & 0,89 & - & 8,89 & 0,077 & & & & & \\
\hline \multicolumn{11}{|l|}{ Metastasis } \\
\hline Brain & 8,09 & 1,05 & - & 62,11 & 0,044 & & & & & \\
\hline Lung & 7,70 & 1,39 & - & 42,70 & 0,020 & & & & & \\
\hline Recurrence & 6,55 & 1,83 & - & 23,53 & 0,004 & 6,55 & 1,83 & - & 23,53 & 0,004 \\
\hline
\end{tabular}

Abbreviation: RT: Radiotherapy

\section{Discussion}

Conservative surgery with radiotherapy is the necessary treatment for $\operatorname{ESTS}^{[14]}$. In recent years, with the increasing importance of limb sparing surgery, preoperative radiotherapy has increased in practice. Preoperative RT associated with higher local control rate and optimal limb sparing surgery rate $(98 \%)^{[15]}$. Therefore, preoperative RT decision should always be discussed in the multidisciplinary team, and the choice of these patients should be considered.

Our research examined variables of sex, age, median tumor size (at diagnosis), histopathological type of the tumor, tumor localization, tumor grade, tumor depth, median radiotherapy doses, radiotherapy modalities, resection margins and we did not find them to be prognostic factors. In our study, the median age of our patients was 28.5 years (range: 19-52) which was a similar study in the 
literature ${ }^{[16,17,18]}$. There was a male dominance. Median tumor size was $9.2 \mathrm{~cm}$ (range $6-14 \mathrm{~cm}$ ).In literature, large size, high grade, deep location were adverse factors for distant metastasis ${ }^{[19]}$. In addition, histological subtype was very important to the choice of preoperative RT. Piston et al. ${ }^{[20]}$ demonstrated that myxoid liposarcoma good response to radiotherapy compared with other soft tissue sarcoma subtypes. We had only 2 (8.3\%) patient histological subtype liposarcoma. In literature, tumor grade (especially high grade), tumor depth (deep location), positive(R2) or close resection margin (R1) associated with adverse prognostic factors ${ }^{[17,21,22]}$. The presence of adverse factors notably increases the risk of local recurrence, distant metastases and a worsening of survival $^{[23]}$. However, in our study, we did not find significant prognostic factors.

Intensity-modulated RT(IMRT) was potentially less morbidity than 3-D conformal RT. Because IMRT provided that less healthy tissue morbidity and higher local control rate ${ }^{[24]}$, in addition, IMRT might allow a reduction in the dose received by bone adjacent and reduced bone fracture risk ${ }^{[24]}$. We treated only seven patients with IMRT and did not find any difference between the two modalities.

Wound healing complication was observed in 8 patient (\%30). This rate was similar in the literature ${ }^{[19]}$. Preoperative radiotherapy increases wound complication ${ }^{[19]}$. Wound healing complication might be related to patient and tumor characteristics (e.g., obesity, diabetes and location of the sarcoma), in addition to RT parameters like a total dose, fraction size, treatment volume, and modern RT techniques $^{[25,26,27,28]}$.

Another clinically important effect was late toxicity. In this study, one patient had grade 2 fibrosis(1.2\%). No patient suffered a posttreatment fracture and edema in 2 years follow-up. In literature, late toxicity was more familiar with postoperative radiotherapy $(48 \%)$ than preoperative radiotherapy $(31 \%)^{[19]}$.In this study, this ratio was minimal, because there were very few patients living more than two years.

In our study, we found that the median OS was 14 months. In addition, 2-years and 3-years OS rate were 39\%, 26\%, respectively. The 2-years and 3-years MFS rate were 33\%, 17\%, respectively.

This ratio was very lower than literature ${ }^{[6]}$. This data may suggest that chemotherapy played a decisive role in OS and MFS.

Several series have reported that preoperative RT in ESTS has 5year local control rates varying between $88 \%$ and $95 \%{ }^{[29,27,30]}$. But, data from our study local control rates after preoperative RT with $71 \%$ at 2 and 3 -years. This study reported a statistically significant and clinically relevant difference in distant metastases and OS.

Two major limitations of the present study were its retrospective design and small sample size. We believe that studies of more specific groups would yield more significant results.

\section{Conclusion}

We only found that recurrence and metastasis are a strong and negative prognostic factor for survival in extremity soft tissue sarcoma patients. Therefore, preoperative RT should be personalized according to histological subtype, tumor site and riskbenefit ratio in ESTS. A multidisciplinary surgical and oncology team-best manages preoperative RT decision.

\section{Declarations}

Ethics approval and consent to participate: H-1683, 01-02-2019

Funding: Not applicable

\section{Competing contributions}

The authors declare that they have no competing interests.

The authors have no financial disclosures to declare, no conflicts of interest to report and have no commercial or proprietary interest.

\section{Acknowledgements: Not applicable}

\section{Author contributions}

Kubilay Inanc designed the research, Kubilay Inanc, Berrin Inanc performed the research, Berrin Inanc and Ertan Koc contributed anallytic tools, Kubilay Inanc analyzed the data and Kubilay Inanc and Berrin Inanc wrote the paper.

The authors have no financial disclosures to declare, no conflicts of interest to report and have no commercial or proprietary interest.

\section{References}

1. Fletcher CDM, Unni KK, Mertens F.Pathology and genetics of tumours of soft tissue and bone. In:World health organization classification of tumours, vol. 5. Lyon, France: IARC Press;2002.

2. Von Mehren M, Randall RL, Benjamin RS, et al.National Comprehensive Cancer Network.Soft Tissue Sarcoma,version 2.2018.J Natl Compr Canc Netw 2018;12:473-83.

3. The ESMO/European Sarcoma Network Working Group.Soft tissue and visceral sarcomas:ESMO Clinical Practice Guidelines for diagnosis, treatment and followup.Ann Oncol 2014;25:iii102-112.

4. Davis AM, O'Sullvian B, Turcotte R, et al. Canadian Sarcoma Group. NCI Canada Clinical Trial Group Randomized Trial. Late radiation morbidity following randomization to preoperative versus postopretaive radiotherapy in extremity soft tissue sarcoma. Radiother Oncol 2005;75:48-53.

5. O'Sullivan B, Davis AM, Turcotte R, et al.Five year results of a randomized phase III trial of preoperative vs post-operative radiotherapy in extremity soft tissue sarcoma. J Clinical Oncol 2004;22(14S):9007.

6. O'Sullivan B, Davis AM, Turcotte R, et al.Preoperative versus postoperative radiotherapy in soft tissue of the limbs:a randomised trial.Lancet 2002;359:2235.

7. Cheng EY, Dusenbery KE, Winters MR, Thompson RC.Soft tissue sarcomas:preoperative versus postoperative radiotheraphy.J Surg Oncol 1996;61(2):90e9.

8. Canon CP, Ballo MT, Zagars GK, et al.Complications of combined modality treatment of primary lower extremity soft-tissue sarcomas.Cancer 2006;107(10):2455e61.

9. Davis AM, O'Sullvian B, Turcotte R, et al.Late radiation morbidity following randomization to preoperative versus postoperative in extremity soft tissue sarcoma.Radiother Oncol 2005;75:48e53.

10. Moore J, Isler M, Barry J, Mottard S.Major wound complication $\mathrm{r}$,sk factors following soft tissue sarcoma resection.EJSO 2014;40:1671e6. 
11. Cox JD, Stetz J, Pajak TF. Toxicity criteraria of the Radiation Therapy Oncology Group (RTOG) and the European Organization for Research and Treatment of Cancer (EORTC).Int $\mathrm{J}$ Radiat Oncol Biol Phys. 1995;31:1341-1346.

12. Tumor of bone and soft tissues.R classification.In: Sobin LH, Wittekind Ch, editors.TNM classification of malihnant tumours UICC 6 th edition.New York:Wiley Liss;2002, p.110.

13. International Commision on Radiation Units and Measurement.ICRU Report 50:Prescribing, Recording and Reporting Photon Beam Therapy. Bethesda, MD: ICRU;1993.

14. Hong A. Role of radiation theraphy in the management of soft tissue sarcoma.Cancer Forum. 2010;34:142-4.

15. McGee L, Indelicato DJ, Dagan R, et al.Long-term results following postoperative radiotherapy for soft tissue sarcomas of the extermity. Int J Radiat Oncol Biol Phys 2012;84:1003-9.

16. Spiguel A. Soft Tissue Sarcomas. In: Peabody TD, Attar S, editors. Orthopedic Oncology. Cham: Spinger International Publishing; 2014.p. 203-23.

17. Stefanovski PD, Bidoli E, De Paoli A, Buonadonna A, Boz G, Libra M, et al.Prognostic factors in soft tissue sarcomas: A study of 395 patients. Eur J Surg Oncol 2002;28:153-64.

18. Pisters PW, Leung DH, Woodruff J, Shi W, Brennan MF. Analysis of prognostic factors in 1,041 patients with localized soft tissue sarcomas of the extremities. J Clin Oncol 1996;65:2-31.

19. Hansen EK, Roach M, editors. Handbook of evidencebased radiation oncology. 3 rd ed. New York: Springer; 2018.

20. Pitson G, Robinson P, Wilke D, et al. Radiation response an additional unique signature of myxoid liposarcoma. Int J Radiat Oncol Biol Phys 2014;60: 522-6.

21. Peiper M, Zurakowski D, Zornig C. Survival in primary soft tissue sarcoma of the extremities and trunk. Langenbecks Arch Chir 1997;382:203-8.

22. Demiral AN, Şen M, Cetinayak O, Bayman E, Havitcioğlu H, Manisalı M, et al. Prognostic factors in soft tissue sarcoma patients treated with postoperative radiotherapy.Turk Onkoloji Dergisi 2006; 21:119-24.

23. Heslin MJ, Woodruff J, Brennan MF. Prognostic significance of a positive microscopic margin in high-risk extremity soft tissue sarcoma implications for management. J Clin Oncol. 1996;14(2):473-8.
24. Hong L, Alektiar KM, Hunt M, et al. Intensity-modulated radiotherapy for soft tissue sarcoma of the thigh. Int $\mathrm{J}$ Radiat Oncol Biol Phys 2004;59:752e759.

25. Baldini EH, Lapidus MR, Wang Q, et al. Predictors for major wound complications following preoperative radiotherapy and surgery for soft-tissue sarcoma of proximity to skin surface. Ann Surg Oncol 2013;20:14949.

26. Wang D, Zhan Q, Eisenberg BL, et al. Significant Reduction of Late Toxicities in Patients with Extremity Sarcoma Treated with Image-Guided Radiation Therapy to a Reduced Target Volume: Results of Radiation Therapy Oncology Group RTOG-0630 Trail. J Clin Oncol 2015;33:2231-8.

27. O'Sullivan B, Griffin AM, Dickie CI, et al. Phase 2 study of preoperative image-guided intensity-modulated radiation therapy to reduce wound and combined modality morbidities in lower extremity soft tissue sarcoma Cancer 2013; 119:1878-84.

28. Folkert MR, Singer S, Brennan MF, et al. Comparison of loacl recurrence with conventional and intensitymodulated radiation therpy for primary soft- tisue sarcomas of the extremity. J Clin Oncol 2014;32:3236-41.

29. Yang JC, Chang AE, Baker AR, et al. Randomized prospective study of the benefit of adjuvant radiation therapy in the treatment of soft tissue sarcomas of the extremity.J Clin Oncol 1998;16(1):197-203.

30. Pollack A, Zagars GK, Goswitz MS, et al. Preoperative vs. postoperative in the treatment of tissue sarcomas a matter of presentation. Int $\mathrm{J}$ Raiat Oncol Biol Phys 1998;4283).563-72.
Abbreviations
ESTS: Soft tissue sarcoma of the extremities
RT: Radiotherapy
IMRT: Intensity- modulated radiotherapy
3-DCRT: 3-dimensional conformal radiotherapy
FDG-PET: 18F-fluoro-deoxy-D-glucose positron emission tomography
MRI: Magnetic resonance imaging
CT: Computerized tomography
PTV: The planning target volume
CTV: The clinical target volume
MV: Million volts 